\title{
Development of a Subscale Supersonic Aeropropulsion Wind Tunnel
}

\author{
George Matsumoto, ${ }^{*}$ Frank K. Lu ${ }^{\dagger}$ and Donald R. Wilson ${ }^{\ddagger}$ \\ The University of Texas at Arlington, Arlington, TX 76019
}

\begin{abstract}
The preliminary design of a Mach 1.5-4 blowdown wind tunnel is presented. The paper concentrates on the design of each of the tunnel components and also highlights the use of the tunnel for the study of the unsteadiness of the flow in the inlet and diffuser of pulse detonation engines. The design of the facility is almost completed and fabrication and assembly have started.
\end{abstract}

\section{Introduction}

$\mathrm{D}^{\mathrm{s}}$ ESPITE the widespread use of computational methods in aerodynamic design, there remain many instances where ground testing is necessary to validate the methodology, ${ }^{1}$ to refine the design or to provide further insight into the flow physics. Propulsion is an area where designs can benefit tremendously from ground testing. There are many aspects of propulsion where the complex flowfields and the lack of maturity of computational tools limit the utility of a purely computational approach.

While there is a recognized need for wind tunnel testing, the number of industrial wind tunnels available in the U.S. has dwindled over the past two decades. There has been almost no effort to redress this steady decline. ${ }^{2}$ The cost of constructing and operating large wind tunnels may be a reason for the lack of further investment. Small wind tunnels, typically found in universities, are becoming attractive, despite their limited capabilities. ${ }^{3}$ These tunnels are inexpensive to operate and maintain. Moreover, the cost of model fabrication is small. There is realization that these tunnels are being exploited to provide meaningful data, not in terms of obtaining aerodynamic data, which is the forte of the large tunnels, but of

*Graduate Research Assistant, Aerodynamics Research Center, Mechanical and Aerospace Engineering Department. Student Member AIAA.

†Associate Professor and Director, Aerodynamics Research Center, Mechanical and Aerospace Engineering Department, Associate Fellow AIAA.

${ }^{\ddagger}$ Professor and Chair, Mechanical and Aerospace Engineering Department, Associate Fellow AIAA.

Copyright () 1998 by G. Matsumoto, F.K. Lu and D.R. Wilson. Published by the American Institute of Aeronautics and Astronautics with permission. refining computational tools which then generate the desired data.

\section{Overview of the Aerodynamics Research Center}

Experimental high-speed aerodynamics research began at UTA with the development of a small shock tube in 1975. An expansion in experimental capability occurred when the Aerodynamics Research Center (ARC) was established in 1988. ${ }^{4}$ The ARC at present houses a low-speed wind tunnel, a high Reynolds number transonic Ludwieg tube wind tunnel, an arc heated tunnel, a shock tunnel, which was recently modified to include a detonation driver, and a pulse detonation engine rig. As part of a continuing program to improve the center's infrastructure, a supersonic wind tunnel and a laser induced fluorescence capability are being developed currently. Figure 1 shows that, with the completion of the new supersonic wind tunnel, the ARC has the unique capability among academic institutions to perform

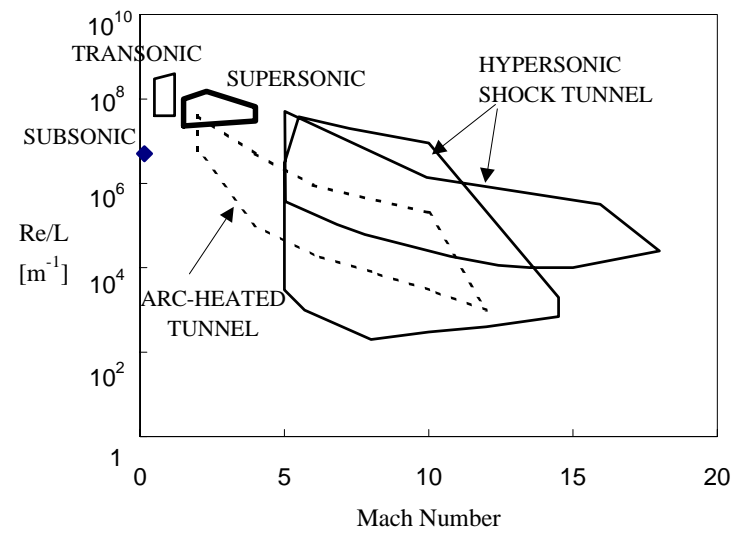

Fig. 1 Aerodynamic simulation capabilities of the ARC. 


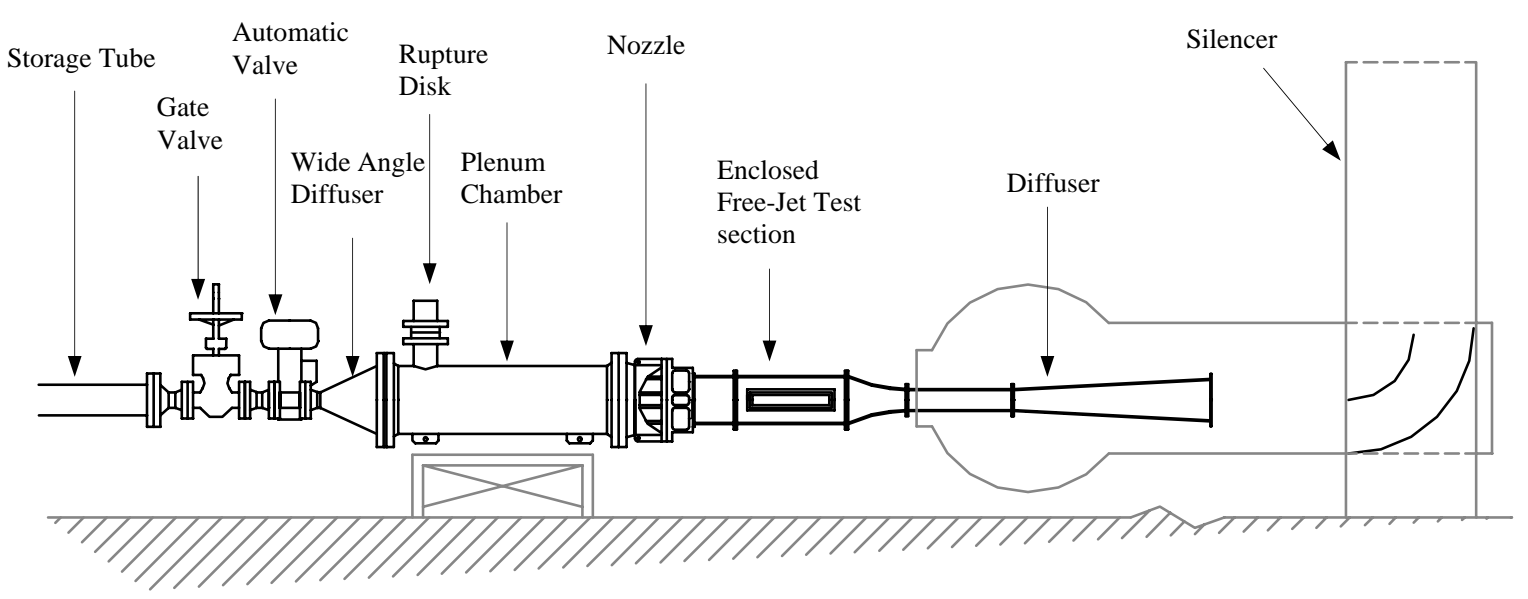

Fig. 2 Schematic of supersonic wind tunnel.

aerodynamic testing from low speed through hypersonic. This paper details the design effort for the supersonic wind tunnel.

\section{Tunnel description}

There are several constraints to consider in designing a supersonic wind tunnel for the ARC. The most severe limitation comes from the maximum allowable pressure and volume of the existing storage tank. It is also important to minimize the starting process and the pressure loss at the plenum chamber and the diffuser to achieve as long a run time as possible.

Safety is a foremost concern as well. The plenum chamber is hydrostatically tested to 150 percent of its maximum operating pressure and it incorporates a rupture disk to protect the downstream components, designed to a lower pressure rating.

A schematic of the wind tunnel is shown in Fig.2. The major components of the wind tunnel are storage tank, gate valve, automatic valve, plenum chamber, nozzle, test section, diffuser, and silencer. Other than the existing storage tank and nozzle, the other components were all newly designed and developed. Following are descriptions of these major components.

\section{Compressor and Air Storage}

The high-pressure air supply in the ARC comes from a 238-atm, 5-stage Clark Model CMB-6 compressor, derated to $143 \mathrm{~atm}$ (2800 psi). After compression, oil and moisture in the air are removed by a filter, the clean dry air flows into three bottles with a total volume of $4.5 \mathrm{~m}^{3}\left(158.6 \mathrm{ft}^{3}\right)$. The dry air is then distributed to all of the ARC's facilities. A separate storage tube is available for the supersonic wind tunnel. This tube has a volume of $1.8 \mathrm{~m}^{3}\left(63.5 \mathrm{ft}^{3}\right)$ and it is rated for a pressure of $51 \mathrm{~atm}$ (750 psi). The three bottles of dry air can fill the storage tube about 13 times. By charging the main storage bottles three times, it is estimated that the supersonic wind tunnel is capable of achieving a maximum of 39 runs daily.

\section{Isolation and Control Valves}

The storage tube, located at the upstream end of the supersonic tunnel, is isolated from the rest of the tunnel by a $0.15 \mathrm{~m}$ (6 in.) diameter Velan Bolted Bonnet Gate Valve. Before a test, the nozzle is set to the desired Mach number, which varies from 1.5 through 4.0. The gate valve is then manually opened. The flow is started when the Fisher V200 Ball Valve $0.15 \mathrm{~m}$ (6 in.) diameter automatic valve is opened. Since the storage tank pressure and temperature are continuously dropping during a test, the valve must open continuously to maintain a constant pressure in the plenum chamber. A pressure transducer is installed at the end of the plenum chamber as part of the stagnation pressure control system. A Fisher DVC-5000 digital valve controller operated by air supply at $518 \mathrm{kPa}$ (75 psi) converts an input current signal from the pressure transducer to a pneumatic output pressure which rotates the ball valve to the desired degree of opening. The controller can be tuned up using non-linear gains and feedback loops to minimize the starting process and pressure fluctuations during a test.

\section{Plenum Chamber}

The quality of the flow into the test section depends heavily on the uniformity of the flow in the 
plenum chamber. Uniform flow can be achieved by having a large section area although this is limited by the existing nozzle geometry. With this in mind, the plenum chamber is designed to be 0.609 $\mathrm{m}$ (24 in.) in diameter and $2.13 \mathrm{~m} \mathrm{(7} \mathrm{ft)} \mathrm{in} \mathrm{length.}$ The plenum chamber has a pressure rating of 34 atm (500 psi), which is the same as that of the nozzle.

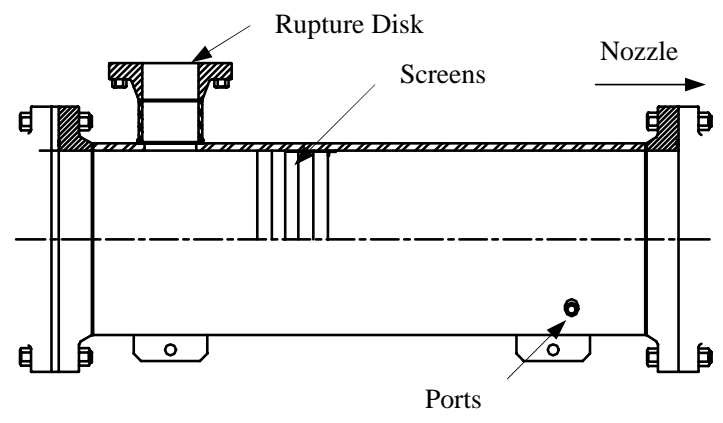

Fig. 3 Schematic of plenum chamber.

The flow in the plenum chamber is estimated to have an average speed of $1.5-15.2 \mathrm{~m} / \mathrm{s}(5-50 \mathrm{ft} / \mathrm{s})$. The maximum flow speed is less than the 24.4$30.5 \mathrm{~m} / \mathrm{s}(80-100 \mathrm{ft} / \mathrm{s})$ recommended by Pope and Goin. ${ }^{5}$ The lower limit is no less than the recommended value of $3.0 \mathrm{~m} / \mathrm{s}(10 \mathrm{ft} / \mathrm{s})$ to minimize the effect of heat convection from the wall to the adjacent air. However, such a problem is particularly important for high-temperature blowdown wind tunnels but is not a big issue for the present design.

Other than having an adequate length to reduce turbulence, the plenum chamber has a coneshaped flow spreader in the wide-angle conical diffuser leading from the control valve. The flow spreader breaks up the jet of air from the storage tank. In addition, three screens are located in the middle of the plenum chamber. The solidities of the screens are $0.56,0.47$ and 0.30 from upstream to downstream. These are used to damp out turbulence and promote flow uniformity. The effect of a damping screen has been reported in Ref. 6 . The results indicate that the turbulence decreases in a certain distance downstream of a screen and the magnitude of the damping is proportional to the pressure drop between the screen. Downstream of the screens are four $25.4 \mathrm{~mm}$ (1 in.) diameter for probes to monitor the plenum pressure and temperature.

The static pressure of the chamber is higher than that of any other downstream portion of the tunnel. In addition, the downstream portion of the wind tunnel is designed for a lower rated pressure.
These two facts necessitated that a rupture disk be installed. A $0.20 \mathrm{~m}$ (8 in.) rupture disk is installed near the upstream end of the plenum chamber to relieve excess pressure in case of drastic failure or missed operation.

\section{Nozzle}

The variable-area supersonic nozzle, AMRAD Model GF-6 was obtained from the LTV Aerospace and Defense Company, Dallas, Texas (presently Lockheed Martin Vought Systems). The nozzle is hand actuated and has a Mach number range of 1.25 to 4.0. The overall length of the nozzle is $889 \mathrm{~mm}$ (35 in.). The nozzle consists of a rigid contoured throat section and downstream flexible plates. The rigid contour is designed to move about a pivot to closely match the proper contour determined by the method of characteristics to provide a uniform exit flow. The throat area can be pre-set to a fixed position prior to a test for fixed Mach number operation. The nozzle exit has a $152 \mathrm{~mm}$ (6 in.) square cross section.

\section{Test Section}

The primary consideration in designing the test section is to make sure that the test section can enclose a relatively large subscale engine model. Therefore, an enclosed free jet test section was chosen for the test section, unlike a conventional solid wall test section. A schematic of the test section is shown in Fig. 4. The advantage of a free jet test section is that the larger cross sectional area at the test section minimizes choking and this makes it possible to install relatively large test models. According to Ref. 7, a test section with a free jet length to width ratio of 5 can be started.

The length of the free jet is about $762 \mathrm{~mm}$ (30 in.). The test section is enclosed by a $280 \mathrm{~mm}$ (11

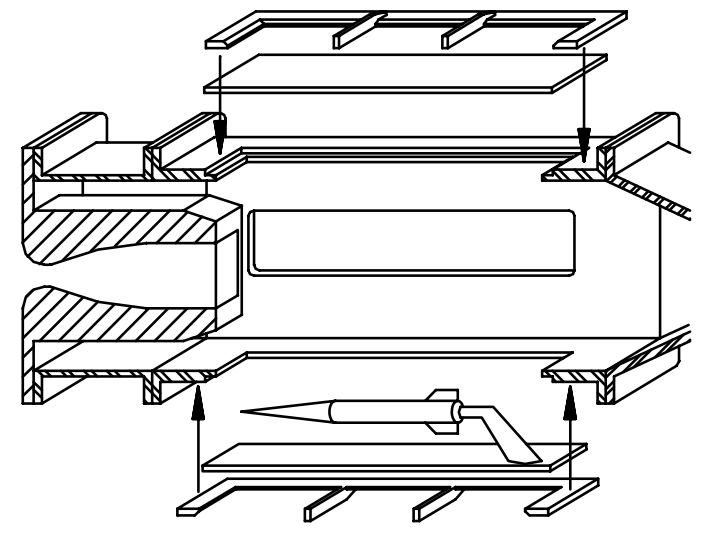

Fig. 4 Test section schematic. 
in.) by $445 \mathrm{~mm}$ (17.5 in.) casing, with $152 \mathrm{~mm}$ (6 in.) by $762 \mathrm{~mm}$ (30 in.) Lexan plastic windows on the two sides of the test section to provide substantial optical access. The test section has a 152 $\mathrm{mm}$ (6 in.) square section and it is $0.9 \mathrm{~m} \mathrm{(3 \textrm {ft } )}$ long. It is made in a modular manner that allows quick modifications. A model can be attached to a sting and installed from the one of two openings of the test section. It is also possible to mount models through attachments in the diffuser.

\section{Diffuser}

The flow exhausts from the test section to the diffuser. One of the factors that contribute to an increase in the power requirement of a supersonic wind tunnel is the irreversibility in the diffuser. A typical constant area diffuser consists of a conventional subsonic geometry diffuser preceded by a long constant area duct. This type of diffuser gives nearly the same re-compression ratio as a normal shock even though the geometry is quite simple compared with a variable area diffuser. The compression occurs through a system of shocks interacting with the boundary layers. This is not the most efficient way to recover the pressure but it is often more practical and very stable under different conditions. It is possible to design more efficient ducts for specific conditions, but they may perform very badly at off-design points. Based on results from MIT, ${ }^{8}$ the diffuser geometry chosen for the present wind tunnel includes a $610 \mathrm{~mm}$ (23 in.) convergent entry section, $1 \mathrm{~m}$ (39.6 in.) of constant area duct followed by a $1.93 \mathrm{~m}$ (76 in.), 6 deg. angle divergent diffuser.

\section{Instrumentation and Data Acquisition}

An adequate tunnel calibration will be performed prior to routine testing. It is proposed that pitot surveys at different stations from upstream to downstream be performed to determine flow uniformity and the useful test core, initially at Mach 2.5 and 3 . Other data that will be gathered include the plenum chamber pressure and temperature. Static surveys will be conducted if deemed necessary.

A multiplexed data acquisition system will be dedicated to the wind tunnel, with an appropriate mix of channels for pressure, temperature and strain gauge conditioning. If necessary, an existing high-speed data acquisition system by DSP Technologies can be used. This high-speed system has 48 channels capable of $100 \mathrm{kHz} /$ channel sampling rate and 12 channels capable of 1 $\mathrm{MHz} / \mathrm{channel}$ sampling, with simultaneous sample-and-hold capability. This system will be nec- essary for resolving unsteady phenomena in proposed tests involving pulse detonation engines.

Two Lexan plastic widows are available for flow visualization using shadowgraphy or schlieren imaging. A window is available from the test section ceiling. This allows a laser light sheet to pass into the test section for visualizations based on light scattering, such as laser induced fluorescence.

\section{Performance}

Performance estimates ${ }^{5}$ indicate that the storage capacity allows a typical test time of about $7 \mathrm{sec}$, a Mach number range of 1.5 to 4 and a Reynolds number range of $25-150 \times 10^{6} / \mathrm{m}$.

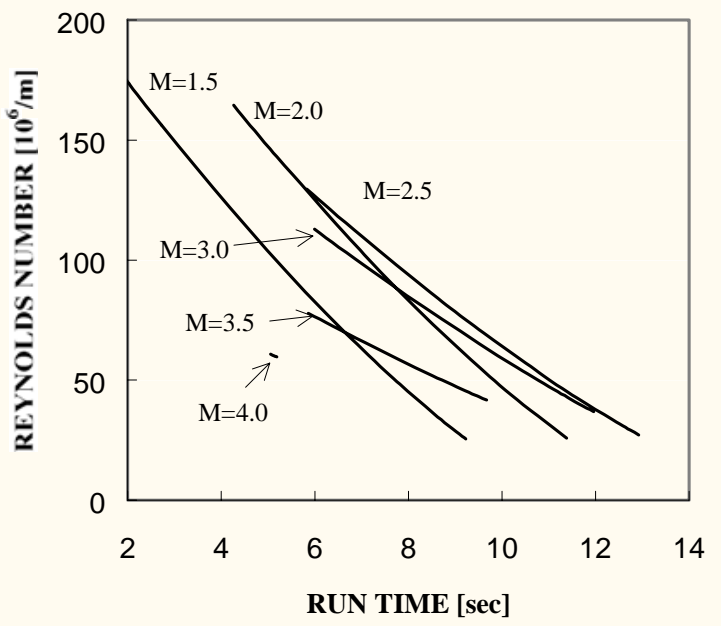

Fig. 5 Performance Map.

\section{Potential Research Topics}

The wind tunnel, after calibration, will be used initially for testing a subscale PDE simulator attached to a supersonic inlet. An analytical study by Couch et al. ${ }^{9}$ suggests that, by proper synchronization, a four-chamber PDE can minimize unsteadiness in the inlet flow, thereby preventing surges and potential unstarts. A preliminary configuration of an inlet/PDE is depicted in Fig.6. This configuration is currently being designed for the wind tunnel and will be tested in the near future. The goal of the test is to validate the analysis. For the first phase of the test, the model PDE will be run without detonation. The detonation processes will be simulated using a high-pressure source and fast acting valves. Subsequently, actual, repetitive detonations will be used to provide a better level of understanding of the unsteady 


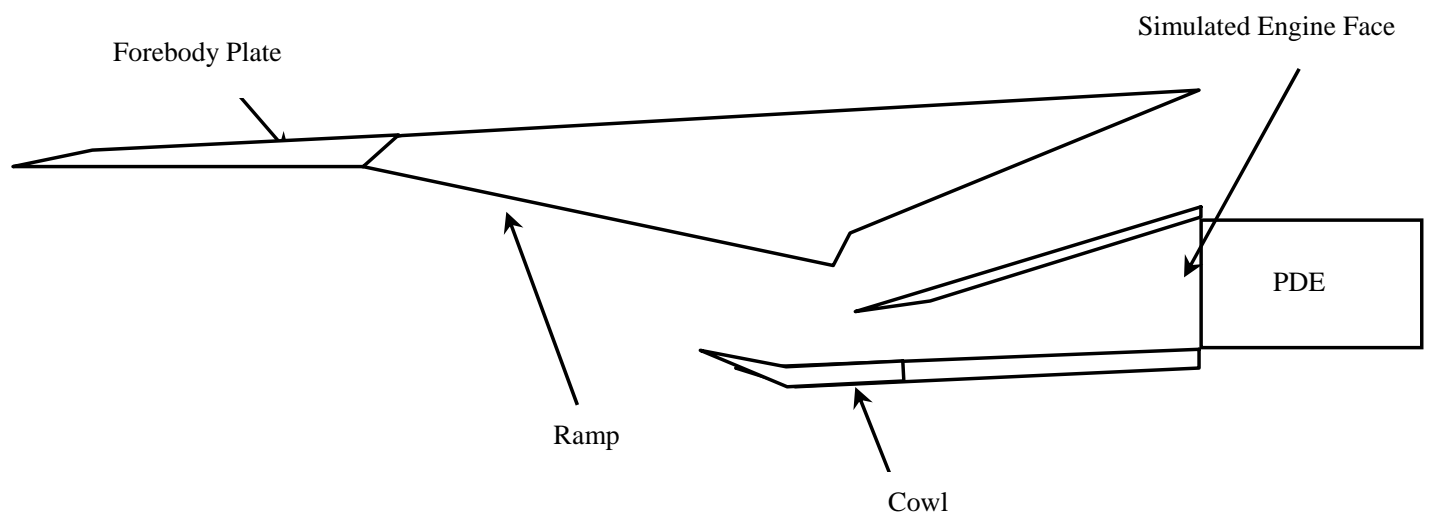

Fig. 6 Schematic of Inlet/PDE model.

flow processes. PDE/nozzle integration studies will also be attempted.

\section{Conclusions}

The upstream components of the wind tunnel has been delivered and will be assembled prior to the down stream portion by July 1998. The automatic valve and its controller will be installed and tested at this time. The designs of the test section and diffuser are in the final phase and the inlet design of PDE will be started. The tunnel is estimated for completion in September 1998. Some calibration data will be available by October 1998.

\section{Acknowledgments}

The development of the tunnel was supported by internal funds from the College of Engineering, the University of Texas at Arlington. Further funding was provided by the Texas Advanced Technology Program. The authors acknowledge the help of students and staff at the Aerodynamics Research Center, especially Jim Holland and Scott Stuessy.

\section{References}

${ }^{1}$ Bradley, R.G., "Future Directions for Applied Computational Fluid Dynamics," Progress in Astronautics and Aeronautics, Vol.125, AIAA Washington DC, 1990, pp.889-900.

${ }^{2}$ Penaranda, F.E. and Freda, M.S., "Aeronautical Facilities Catalogue Wind Tunnels,” NASA RP-1132, 1985.

${ }^{3}$ Squire, L.C., "The Role of Small High-Speed Wind Tunnels in Aeronautical Research,” Proceedings of the Royal Aeronautical Society Conference on Wind Tunnels and Wind Tunnel Techniques, Cambridge, U.K., 1997, pp. 36.1-36.10.

${ }^{4}$ Wilson, D.R., "Development of the University of Texas at Arlington Aerodynamics Research Center," AIAA Paper 88-2002, 1988.

${ }^{5}$ Pope, A. and Goin, K., High-Speed Wind Tunnel Testing, Wiley, New York, 1965, pp. 71-134.

${ }^{6}$ Schubauer G.B., Spangenberg W.G. and Klebanoff P.S., "Aerodynamic Characteristics of Damping Screens," NACA TN 2001, 1950

${ }^{7}$ Lee J.D. and Eschen, G.L., "Critical Performance Parameters of an Intermittent High-Pressure Free-Jet Supersonic Wind Tunnel,” Ohio State University, Final Report on RF Project 344, July 31, 1954.

${ }^{8}$ Neumann, E.P. and Lustwerk, F., "Supersonic Diffusers for Wind Tunnels," Journal of Applied Mechanics, June 1949.

${ }^{9}$ Couch, B.D., Hunter, L. and Pegg, R., "Pulse Detonation Engine Air Induction System Analysis," AIAA Paper 96-2918, 1996. 